\section{O Fator Materno na Transmissão do DM tipo 2: Ambiente ou Herança?}

O Diabetes Mellitus (DM) tipo 2 é um grupo heterogêneo de distúrbios metabólicos caracterizado por hiperglicemia crônica resultante de uma diminuição da ação e secreção de insulina. Apesar de fatores ambientais terem um papel importante na determinação de risco para o desenvolvimento da doença, há claras evidências que a sua susceptibilidade é determinada por fatores genéticos. Na maioria dos casos, os fatores ambientais seriam os aceleradores da doença naqueles indivíduos com predisposição genética. As evidências para a existência de um componente genético na gênese do DM tipo 2 provém de estudos em gêmeos mostrando uma maior concordância entre os monozigóticos quando comparados aos dizigóticos $(1,2)$; também a observação de uma grande variação de prevalência em diferentes grupos étnicos como níveis muito baixos entre a população chinesa que vive em áreas rurais até níveis muito elevados observados entre os índios Pima (3), apontam para a existência de fatores genéticos contribuindo para a predisposição à doença.

A forte agregação familiar da doença é outra evidencia para a existência de um componente genético. Dados do Framinghan Offspring Study mostram que o risco para desenvolvimento do DM tipo 2 aumenta em 3,43,5 vezes quando um dos pais é portador da doença, sendo o aumento de 6,1 vezes nos casos em que ambos os pais apresentam diabetes quando comparados aos indivíduos em que nenhum dos pais é afetado (4). O estudo da transmissão familiar do DM é útil para o melhor entendimento do seu modo de herança e investigação do papel da herança materna.

Nessa edição dos ABE\&M, Crispim e cols (5) investigam a história parental de diabetes entre portadores de DM tipo 2 residentes no Rio Grande do Sul, e sua influência nas características clínicas da doença (5). Os autores puderam observar um efeito materno contribuindo para o DM tipo 2 tanto nos pais dos probandos $(48,4 \%$ e $21,3 \%$ de mães e pais afetados, respectivamente), quanto na sua prole ( $17,2 \%$ e $6,3 \%$ de mães e pais de filhos afetados, respectivamente). Esses resultados confirmam estudos anteriores realizados entre caucasianos (6,7), hispânicos (8) e também em nosso meio, entre residentes da cidade de São Paulo (9), contrastando, porém com os dados obtidos no estudo Framinghan (4). Esses dados levantam questões sobre os possíveis mecanismos envolvidos nessa transmissão materna preferencial observada em alguns estudos.

Conforme apontado por Crispim e cols (5) é possível que tanto fatores genéticos quanto ambientais possam estar envolvidos. Freinkel foi quem inicialmente propôs, em 1980 (10), que o desenvolvimento fetal é comprometido durante uma gravidez com diabetes de forma que as célulasbeta são, em fases mais tardias da vida, incapazes de responder adequadamente a demanda imposta por uma eventual resistência à insulina. Estudos em roedores mostram claramente que uma exposição intra-uterina à hiperglicemia materna leva ao DM em gerações subseqüentes (11). Em humanos, Silverman e cols (12), com o objetivo de testar a hipótese de que o desenvolvimento pós-natal pode ser modificado por experiências metabólicas editorial

Regina S. Moisés 
intra-útero, avaliou prospectivamente filhos de mães com diabetes durante a gravidez. Esses autores verificaram que aqueles indivíduos que apresentaram níveis mais elevados de insulina no líquido amniótico, um indicador da função da célula-beta fetal, tiveram maior freqüência de tolerância à glicose diminuída na infância. Portanto, parece que um ambiente intra-uterino anormal associa-se a alterações na função da célula-beta na vida intra-uterina e na infância e disfunção glicorregulatória mais tardiamente. Esses dados sugerem que um controle glicêmico intensivo durante a gravidez pode ter benefícios adicionais, contribuindo também para um decréscimo na prevalência do DM tipo $2 \mathrm{em}$ fases mais tardias. Porém, devido a idade relativamente tardia de aparecimento do DM tipo 2 parece pouco provável que o diabetes durante a gravidez possa ser o único fator responsável pelo excesso de transmissão materna do diabetes reportado em alguns estudos.

Dentre os fatores genéticos que explicariam a predominância materna na transmissão do DM tipo 2, podemos citar a herança de alterações em DNA mitocondrial. Sabe-se que o DNA mitocondrial é de herança exclusivamente materna, e variantes em sua seqüência têm sido associadas com o desenvolvimento de DM, sendo a mais freqüentemente associada à substituição de A por G na posição 3243. Entretanto essa é uma forma rara de DM cuja freqüência na população diabética varia de 0,2 a $2 \%$ dependendo da etnia $(13,14)$. $\mathrm{Na}$ população predominantemente de caucasóides estudada por Crispim e cols (5) verificou-se uma freqüência de $0,4 \%$ entre os portadores de DM tipo 2 . Freqüência idêntica foi por nós verificada em uma população de intolerantes à glicose etnicamente mais heterogênea (dados não publicados). Esses dados indicam a baixa prevalência dessa forma de diabetes em nosso meio, tornando pouco provável que essa mutação especifica contribua de forma significativa para a maior transmissão materna observada. Porém é possível que outras variantes no DNA mitocondrial possam agir, juntamente com genes nucleares, aumentando a susceptibilidade ao DM tipo 2. Outra possibilidade é a existência de um locus de susceptibilidade ligado ao cromossomo $\mathrm{X}$, associado com um ou mais loci autossômicos (15).

Um potencial viés no estudo de Crispim e cols (5), assim como em outros estudos (6-9), e que foi explicitamente observado pelos autores, é que o grau de tolerância à glicose dos pais e filhos dos propósitos foi avaliado através de questionário e não diretamente testado. Alguns estudos que testaram o estado diabético dos pais dos probandos, tais como o estudo entre $\mathrm{Me}$ xican-American ou em indianos, não evidenciaram excesso de transmissão materna do DM tipo $2(16,17)$.
No DM tipo 2, que já foi referido por Neel e cols como o "pesadelo do geneticista", a existência de um componente materno na sua transmissão adiciona um outro fator de complexidade a essa doença já complexa, porém abre possibilidades para o melhor entendimento dos fatores envolvidos em sua transmissão.

\section{REFERÊNCIAS}

1. Barnett AH, Leslie R, Pyke DA. Diabetes in identical twins: a study of 200 pairs. Diabetologia 1981;20:87-93.

2. Newman B, Selvy JB, King MC, Slemenda C, Fabstz R, Friedman GD. Concordance for type 2 (non-insulindependent) diabetes mellitus in male twins. Diabetologia 1987;30:763-8.

3. King $\mathrm{H}$, Rewers $M$. Global estimates for prevalence of diabetes mellitus and impaired glucose tolerance in adults. WHO Ad Hoc Diabetes Reporting Group. Diabetes Care 1993; 16:157-77.

4. Meigs JB, Cupples A, Wilson PWF. Parental transmission of type 2 diabetes. The Framinghan offspring study. Diabetes 2000;49:2201-7.

5. Crispim D, Canani LH, Gross JL, Tschiedel B, Souto KEP, Roisenberg I. Familial history of type 2 diabetes inpatients form southern Brazil and its influence on the clinical characteristics of this disease. Arq Bras Endocrinol Metab 2006;50/5:862-8.

6. Thomas F, Balkau B, Vauzelle-Kervrodan F, Papoz L, the Codiab-Inserm-Zeneca Study group. Maternal effect and familial aggregation in NIDDM. Diabetes 1994;43:63-7.

7. Alcolado JC, Alcolado R. Impotance of maternal history of non-insulin dependent diabetic patients. Br Med J 1991;302:1178-80.

8. Mitchell BD, Valdez R, Hazuda HP, Haffner SM, Monterrosa SM, Stern MP. Differences in the prevalence of diabetes and impaired glucose tolerance according to maternal or paternal history of diabetes. Diabetes Care 1993; 16:1262-7.

9. Sucasas CM, Lerario D, Reis AF, Dib SA, Moises RCS, Agregação familiar e diabetes mellitus tipo 2: papel do fator materno. Arq Bras Endocrinol Metab 1998; 42:53-6.

10. Freinkel N. Of pregnancy and progeny. Diabetes 1980;29:1023-39

11. Aerts L, Holemans K, Van Assche FA. Maternal diabetes during pregnancy: consequences for the offspring. Diabetes/Metab Rev 1990;6:147-67.

12. Silverman BL, Metzger BE, Cho NH, Loeb CA. Impaired glucose tolerance in adolescent offspring of diabetic mothers. Relationship to fetal hyperinsulinism. Diabetes Care 1995:18:611-7.

13. Saker PJ, Hattersley AT, Barrow B, Horton V, Gillmer MD, Turner RC. UKPDS 21: low prevalence of the mitochondrial transfer RNA gene (tRNA(Leu(UUR) mutation at position 3243bp in UK Caucasian type 2 diabetic patients. Diabet Med 1997;14(1):42-5. 
14. Kishimoto M, Hashiramoto M, Araki S, Ishida Y, Kazumi T, Kanda $\mathrm{E}$, et al. Diabetes mellitus carrying a mutation in the mitochondrial tRNALEU(UUR) gene. Diabetes 1995;38: 193-200.

15. Cox NJ. Maternal component in NIDDM transmission How large an effect? Diabetes 1994;43:166-8.

16. Mitchell BD, Kammaere CM, Reinhart LJ, Stern MP, MacCluer JW. Is there an excess in maternal transmission of NIDDM? Diabetologia 1995;38:314-7.

17. McCarthy M, Cassell P, Tran T, Mathias L, 't Hart LM, Maassen JA, et al. Evaluation of the importance of maternal history of diabetes and of mitochondrial variation in the development of NIDDM. Diabet Med 1996; 13:420-8

\section{Endereço para correspondência:}

Regina S. Moisés

Disciplina de Endocrinologia, Departamento de Medicina Universidade Federal de São Paulo - UNIFESP/EPM

Rua Botucatu, $740-2^{\circ}$. andar.

04034-970 São Paulo, SP, Brazil,

Phone: +55 11 5576-4229, Fax: +55 11 5579-6636

E-mail: rmoises@endocrino.epm.br 